\title{
Arazi Edinimi ve Halk Katılımının Sağlanması Açısından Türkiye ve Dünya Örneklerinin İncelenmesi
}

\author{
Yeşim Tanrıvermiş ${ }^{1}$ \\ ORCID: 0000-0002-0859-7150
}

\author{
Esra Keskin ${ }^{2}$ \\ ORCID: 0000-0003-2778-9024
}

Öz

Kentleşme ve nüfus artışı ile birlikte özellikle tarım arazileri varlı̆gnda bir düşüş olduğu görülmektedir. Tarımsal alanlarda dağgnık mülkiyet yapısı, sulama tesis ve alt yapısının bulunmaması ya da yetersiz oluşu, ulaşımın zor olması gibi sorunların önüne geçilebilmesi amacıyla arazi edinim uygulamaları başlatılmıştır. Mülkiyet hakkına dayanan arazi edinim uygulamaları, dağınık ve küçük halde bulunan arazi parçalarının bir araya getirilerek tarımsal verimliliğin arttırılması, kamu yararı çerçevesinde kamunun ve toplumun ihtiyaçlarının karşılanması ve özellikle yerinde dönüşümün yapılmasını ifade ederken; hukuki, ekonomik ve sosyal içerikli bir süreç olarak işlemektedir. Çalı̧mada farklı arazi edinim yöntemleri içerisinde toplulaştırma uygulamaları incelenerek arazi edinimi sürecinde halk katıllmının önemi ve örnek projeler ışığında halk katıllmmina ilişkin sonuçlar tartışllarak Türkiye ve Dünya örnekleri karşllaştırılmıştır. Örnek projeler ışı̆̆ında farklı uygulamalar değerlendirilerek, katılımın sağlanabilmesi amacıyla farklı çäzüm önerileri getirilmiştir. Çalışmada üniversitelerin projelere dahil edilmesi ve proje başlangıcindan itibaren yerel halkn sürece dahil edilmesinin söz konusu uygulamalara olumlu katkisinin oldukça fazla olduğu ortaya konulmuştur.

Anahtar Kelimeler: Arazi edinimi, halk katılımı, toplulaştırma.

\footnotetext{
${ }^{1}$ Doç. Dr. Ziraat Mühendisi, Ankara Üniversitesi, E-mail: aliefendioglu@ankara.edu.tr

${ }^{2}$ Arş. Gör. Avukat, Ankara Üniversitesi, E-mail: esrkeskin@ankara.edu.tr

idealkent (c) Kent Araştırmaları Dergisi (Journal of Urban Studies) 


\title{
Examining Land Acquisition and Public Participation based in Turkey and Other Countries Examples in the World
}

\author{
Yeşim Tanrivermiş ${ }^{3}$ \\ ORCID: 0000-0002-0859-7150
}

\author{
Esra Keskin 4 \\ ORCID: 0000-0003-2778-9024
}

\begin{abstract}
The communicative language of the space is full of signs and symbols that construct the narrative of the city. This spatial environment, which has many meanings behind it and conveys messages to us, turns into a social and cultural narrative with our experiences, spatial behavior, cognitive perception and memory. The narrative of the city takes shape not only through functional, social and cultural relations of the architectural space but also by ideological messages. Power interferes with concrete design tools such as form, material, location, spatial hierarchy and monumentality while using architecture and the city as a tool of building ideologies. However, in addition to this, the political authority restructures the space and spatial practices "in language", thus in memory, with the terminology it uses in the definition and place naming (sometimes without even physical intervention). This study is an experimental research on the (re)meaning of the narrative of the city with spatial imaginations. Within the scope of this work; place naming examples are explored under two cases; connotations of commemorative initial names (indicatives) and the semantic of term names that describe type of space / typology; also contemporary examples of place naming in Turkey are examined as a political practice.
\end{abstract}

Keywords: Land acquisition, public participation, land consolidation.

\footnotetext{
${ }^{3}$ Assoc. Prof. Agricultural Engineer, Ankara University, E-mail: aliefendioglu@ankara.edu.tr ${ }^{4}$ Res. Asst. Lawyer, Ankara University, E-mail: esrkeskin@ankara.edu.tr 


\section{Giriş}

Hızlı kentleşmenin ve nüfus artışının sonucu olarak dünyanın ve buna paralel olarak Türkiye' nin verimli tarım arazilerine olan ihtiyacı her geçen gün artmaktadır. Küçük arazi parçalarını birleştirmek amacıyla yapılan toplulaştırma uygulamaları ve imar parsellerinde yapılan kamulaştırmalar tüm dünyada farklı şekillerde yapılmakla birlikte halkın katılımının sağlanması, sürecin başarıyla sona erdirilebilmesi ve yönetilebilmesi açısından öncelikli unsurları arasında görülmektedir. İnsan hakları kavramı ile 2. Dünya Savaşı sonrası başlayan temel hak ve hürriyetlerin bir yansıması da kentli hakları ve halk katılımı ile devam etmiştir. Kentli haklarının uluslararası anlamda ele alınması ve bir metin olarak yer alması 18 Mart 1993 tarihinde Avrupa Kentsel Şartı'nın kabul edilmesi ile gerçekleşmiştir. Avrupa Yerel ve Bölgesel Yönetimler Konferansı'nda imzalanan metnin diğer uluslararası metinlerden farkı yerel yönetimlerin imzasına açılmış olmasıdır (Pektaş ve Akın, 2010, s. 27). Söz konusu belge 20 maddelik bir deklarasyon ve 13 maddeden oluşan şart ilkelerini içermekte, belgede "toplumun geleceğini etkileyecek her türlü önemli projede halka danışma gereği" ilkesi gereği ile halk katılımı bir kez daha vurgulanmaktadır. 28 Mayıs 2008 tarihinde onaylanan ve 29 Mayıs 2008 tarihinde kabul edilen Avrupa Kentsel Şartı- II "Yeni Bir Kentlilik İçin Manifesto" ile halk katıl1mının siyasi boyutu desteklenmiş ve bir kez daha katılım ve kentsel yönetişim modeli üzerinde durulmuştur.

Türkiye'de arazi parçalanması sonucunda oluşan küçük araziler tarım açısından büyük bir tehdit oluşturmuştur. Gelecekte olması muhtemel sorunların önüne geçilebilmesi ve mevcut uygulamaların değerlendirilebilmesi amacıyla arazi edinim yöntemlerinden toplulaştırma uygulamaları incelenerek Türkiye ile karşılaştırılmaya çalışılmıştır. Halk katılımının sağlanması arazi edinim yöntemlerinin başarılı sonuçlara ulaşabilmesi için en önemli etkenlerden birisi olarak değerlendirilmektedir. Bu çerçevede farklı projelerde katılım süreçleri ve proje sonuçları tartışılarak Türkiye için çözüm önerileri sunulmaktadır. Tek bir proje yerine farklı projeler incelenerek her bir proje çıktısı kendine özgü sonuçları içerisinde değerlendirilmekte ve çıkarımlar yapılmaya çalışılmaktadır. Bu sayede farklı uygulamalarda karşılaşılan farklı sorunlar görülebilmekte ve iyi uygulama örnekleri ile karşılaştırılabilmektedir. 


\section{Arazi Edinim Uygulamaları}

Kırsal bölgelerde tarım amacıyla kullanılan parsellerin; maliklerinin yapmış oldukları ifraz ve satış işlemleri, miras sonucu parçalanma ve kamulaştırma gibi uygulamaların neticesinde küçülmesi tarımsal faaliyetlerin azalmasına neden olmuştur. Bununla birlikte tarımsal alanlarda dağınık mülkiyet yapısı, sulama tesis ve alt yapısının bulunmaması ya da yetersiz oluşu, ulaşımın zor olması gibi sorunların önüne geçilebilmesi amacıyla arazi toplulaştırma uygulamaları başlatılmıştır. Toplulaştırma uygulamaları; 5403 Sayılı Kanun, 3083 Sayılı Kanun'un Uygulama Yönetmeliği ile Tapu Kadastro Genel Müdürlügü tarafindan yayınlanan genelgeler ile düzenlenmektedir. Arazi edinim yollarından kamulaştırma ise esas olarak 2942 sayılı Kamulaştırma Kanunu kapsamında değerlendirilse de birçok farklı düzenlemede de yer almaktadır. Kentsel dönüşüm ise genel çerçevede 6306, 5393 ve 5366 Sayılı Kanunlar çerçevesinde yapılmaktadır.

Arazi toplulaştırması dar anlamıyla incelendiğinde parçalanmış taşınmazların herhangi bir altyapı çalışmasına yer verilmeden birleştirilmesi olarak tanımlanırken; geniş anlamıyla arazi toplulaştırması parçalanmış mülklerin birleştirilmesine ilave olarak, sulama, ulaşım ve kırsal yerleşimin ihtiyaçları olan tüm altyapı hizmetleri olarak tanımlanmaktadır (Boyraz ve Üstündağ, 2008, s. 565). Arazi toplulaştırması kavramını yalnızca tarımsal faaliyetler ile tanımlamak yeterli görülmemektedir. Arazi toplulaştırmasını aynı zamanda kırsal alanlarda yaşayan nüfusun hem çalışma şartlarını da iyileştiren hem de göçü etkileyen çok yönlü bir kırsal alan planlaması olarak ifade etmek daha doğru olacaktır (Boyraz ve Üstündağ, 2008, s. 569).

\section{Arazi Edinim Yöntemleri Açısından Türkiye Örneğinin İncelenmesi}

Türkiye tarımındaki yapısal sorunların başında işletmelerin küçük ve parçalı olması gelmektedir. Türkiye'de ortalama arazi büyüklüğü 5,16 ha ve işletme başına parsel sayısı 5,4 adet düşmektedir. Türkiye' de kırsal alanda arazilerin kimlere ait olduğu, kimler tarafından kullanıldığı, hangi arazinin gerçek sahibi tarafından ekildiği, hangi arazinin kiracıları tarafından kullanıldığı çoğunlukla bilinmemektedir. Bu durumun sebepleri arasında mirasa ilişkin düzenlemeler ile özellikle 5403 Sayılı Kanunda yer alan düzenlemeler sayılabilmektedir. Söz konusu iki düzenleme beklenenin aksine arazinin bölünmesini engellemekte yetersiz kalmıştır. Yürürlükteki yasa ve yönetmeliklere göre, arazi toplulaştırma projelerinin uygulanması 
gönüllüğe bağlı olduğu için, yatırımın benimsenmesi önem kazanmakta ve ön plana çıkmaktadır. Bu nedenle de bu tür projelerin gerekli olduğu yerlerde programa alınabilmesi için, mutlaka yatırımın benimsenmesini engelleyen faktörlerin belirlenerek önlemler alınması gerekmektedir (Aktaş vd., 2006, s. 2).

Toplulaştırma uygulamaları öncesi yaşanan sorunlar; parsellerin küçük ve şekilsiz olması, makine kullanımı için verimsiz arazilerin varlığı, parseller arasında ulaşımın zor olması, düzenli sulama olmayışı nedeniyle tarım alanlarının kaybı, küçük parsellerde yatırım yapılmasının güçlüğü, parçalı yapıdan ötürü komşularla yaşanan sorunlar, komşuların araziyi yönetim şeklinin diğer parselleri de etkiliyor oluşu ve kan davası gibi sorunların varlığı nedeniyle arazinin kullanılamıyor oluşu olarak sıralanabilir.

Bu sorunlardan yola çıkılarak örnek uygulamaların incelenmesi ve tespitlerin tartışılması araştırma konusuna ilişkin bir anlayış geliştirilebilmesi açısından önemli görülmektedir.

Örnek olay 1 (Eğitim seviyesi yüksek olan yerlerde toplulaştırma); olarak ele alınan çalışmada Kahramanmaraş Türkoğlu ilçesi ve köylerinde yapılmış olan projeyi ele almış ve çalışma ile katılımcıların \% 73'ünün arazi toplulaştırması hakkında yeterli bilgiye sahip bulunmadığı ortaya konulmuş ve eğitim seviyeleri açısından önemli bir ilişki bulunduğu tespit edilmiştir. Ayrıca sulama suyunun temininin, araziye ulaşımın kısa oluşunun ve eğitim seviyesinin yüksek olmasının toplulaştırma uygulamasına olan desteği arttırdığ görülmüştür (Arslan ve Değirmenci, 2016, s. 33). Yapılmış olan çalışma eğitim seviyesi arttıkça toplulaştırma projelerine olan desteğin de arttığını göstermektedir. Eğitim oranı yüksek olan alanlarda katılım da daha yüksek seviyede gerçekleşmektedir. Ancak eğitim oranının düşük olduğu yerlerde aksine bir durumdan söz edebilmek mümkündür.

Örnek olay 2 ‘de (Paydaşlar arasında kurumsal katılımın genişliği-güvenilirlik ilişkisi); Adana İli Karataş İlçesi Yemişli Köyü’nde yapılmış olan başka bir çalışma ele alınmıştır. Çalışmada çiftçilerin toplulaştırma konusunda olumlu fikir sahibi olmalarında, proje yürütücüsü kurumlarda çalişanların oldukça büyük etkisinin olduğu belirlenmiştir (Aktaş vd., 2006, s. 2). Anket yapılan çiftçilerin arazi toplulaştırmasına olumlu bakışında etkili olan kişi ya da faktörlerin başında sırasıyla, projeyi yürüten kurum ilgilileri ve çalışanları (\% 52,4), lider pozisyondaki çiftçiler ( $\% 19,0)$, aile ve 
yakın komşular (\% 14,3), köy muhtarı (\% 9,5) ve diğer proje uygulamalarına tanıklık edenler $(\% 4,8)$ gösterilmiştir. Anket yapılan çiftçilerin \% $89,0^{\prime} u$ arazinin manevi değeri olduğuna inanırken \% 11,0'i ise bu duruma inanmamaktadır (Aktaş vd., 2006, s. 4). Proje paydaşları arasında üniversiteler gibi kurum yetkililerinin yer almasının projeye olan güveni arttırmanın yanı sıra katılım oranının artmasında da etkili olduğu söylenebilmektedir. Katılımın yüksek olduğu projeler daha kısa sürede tamamlanabilmekte ve bu sayede maliyetlerde düşüş mümkün olabilmektedir.

Örnek olay 3 (Toplulaştırma sonrası beklentinin karşılanabilirliği); olarak ele alınan Kırıkkale İli Delice İlçesi'nde yapılmış olan çalışma ise toplulaştırma sonrasına ilişkin sıkıntılara dikkat çekmektedir. Toplulaştırma sonrasında mevcut eksikliklerin giderilmediği, geleceğe ilişkin bilgilendirme ve önerilerin yapılmadığ sonrasında arazi değerlerinde artış olması nedeniyle proje öncesinde mevcut olan endişelerin proje sonucunda büyük oranda yok olduğu tespit edilmiştir (Kılıç Seyyar, 2019, s. 102). Çalışma sonucunda sağlanan başarıda halkın projeye dahil edilmesi ile proje sonucundaki başarı arasında çok ciddi bir ilişki olduğu görülmektedir

Örnek olay 4 (Bilgilendirme ve memnuniyet ilişkisi) olarak ele alınan bir diğer çalışmada ise toplulaştırmanın arazi malikleri tarafından tam olarak anlaşılamadığı ancak gerekli bilgilendirme ve katılımın sağlandığ 1 durumlarda toplulaştırma oranları sonucundaki memnuniyetin \% 75'lere kadar çıktığ1 görülmektedir (Şağban, 2018, s. 52). Söz konusu çalışma sonuçları halkı bilgilendirmenin proje sonundaki memnuniyet ile doğrudan ilişki halinde olduğunu göstermektedir. Tarafların bilgi eksikliğinin giderilmesi ile uygulamaya yönelik önyargı ve kaygılarında önemli bir düşüş olduğu söylenebilmektedir.

Örnek olay 5 (Bilgi düzeyi düştükçe halk katılımının oranın düşmesitoplulaştırma uygulamalarını destekleme nedenleri) olarak AnkaraKonya Yüksek Hızlı Tren güzergâhında bulunan, toplulaştırmaya tabi tutulan Kolukısa, Sarıkaya ve Örnekköy Mahallelerini ele alan çalışma incelenmiştir. Konu mahallelerde yaşayan kişilerle yapılan anket çalışmasının sonuçları incelendiğinde mahalle halkına toplulaştırma projesiyle de ilgili hiçbir bilgi verilmediği görülmüştür. Toplulaştırma sonucunda parselinizin oluşacağı parça sayısı bilgisi verildi mi sorusuna; evet cevabı \% 1,10 hayır cevabı ise \% 98,90 olarak alınmıştır (Ayten, 2015, s. 149). Ayrıca katılımcıların arazi toplulaştırması sonrası ise araştırma sonuçlarına göre \% 58,19 'unun hiç bilgisi olmadığ 1 ve \% 41,81'inin ise bilgisi olduğu ortaya 
çıkmıştır. Arazi toplulaştırmasıyla hangi kurumun ilgilendiği sorusuna \% 88,14 'ü bilmediğini ve \% 10,73'ü ise Tarım Reformu Genel Müdürlüğü'nün yaptığını bildiklerini ifade etmişlerdir (Ayten, 2015, s. 163). Yapılan çalışma halkın bilgi düzeyinin yetersiz kaldığını gözler önüne sermektedir. Toplulaştırma sonucunda oluşacak parsellere ilişkin gerekli bilgilendirme yapılmadığı hatta toplulaştırma işlemine ilişkin bir ön bilgilendirmenin dahi verilmediği çalışmayla ortaya konulmuştur. Bilgi eksikliğinin dikkati çektiği bir projede halk katılımından bahsetmenin mümkün olamadığı kanaatine varılmaktadır. Toplantılar ile bilgilendirmenin yapıldığ 1 örneklerde katılımın da daha yüksek oranlarda olduğu görülmektedir.

Dünya Bankası gereklilikleri incelendiğinde ise en önemli adım halkın bilgilendirilmesi olarak kabul edilmiştir. Ancak Türkiye'deki örnek uygulamalar incelendiğinde yeterli bilgilendirmelerin yapılmadığ 1 ve bu duruma paralel olarak geri dönüş mekanizmalarının da işlemediği görülmektedir.

Yasal düzenlemeler ile halk katılımının sağlanabilmesi amaçlanmakta ve birçok projede gerek askı yoluyla ilana çıkılması gerekse de uzlaşmanın sağlanmasının öncelikli olması ile halkın sürece dahil edilmesi hedeflenmektedir. Ancak uygulamalar göstermektedir ki halk katılımının sağlanabilmesi için atılması gereken adımlar bulunmakta, çözüm yollarının üretilebilmesi için öncelikle arazi edinim uygulamalarında karşılaşılan sorunların incelemesi gerekliliği bulunmaktadır. Arazi toplulaştırmasının temel amaçları arasında; dağınık olan parselleri mümkün olduğu kadar bir araya toplamak, eşdeğerde parseller tahsis etmek, yola cephesi olmayan parsel birakmamak, modern sulama sistemlerini sağlamakla birlikte zaman ve işgücü verimini arttırmak yer almaktadır. Tarım arazileri açısından çok önemli olan toplulaştırma uygulamaları sonucunda maliklerin çoğu olumlu düşünmekte olup, bir kısım ise parsel sayısının düşmüş olmasından ve verilen yerlerden şikâyetçi olmaktadır.

Ayten (2015)'in yapmış olduğu çalışmada arazi toplulaştırma işlerini destekleme nedeni olarak, birinci sırada \% 41,81'lik oranla arazilerin toplu bir yerde olması, ikinci sırada \% 29,38'lik oranla arazilerin toplu olmasindan dolayı masrafın azalması, üçüncü sırada \% 20,90'lık oranla arazilerin toplu olmasindan dolayı verimin ve gelirin artması ve son olarak ise $\%$ 7,91'lik oranla her bir parselin yolunun olması sonucu ortaya çıkmıştır. 
Toplulaştırma uygulama sonuçlarının olumlu olacağı konusunda beklentinin yüksek olduğu dikkat çekicidir. Toplulaştırma ile işgücü ve verimin artacağı, zaman kaybının azalacağı düşünülmektedir.

Özellikle toplulaştırma yapılan alanların bir cazibe merkezi haline getirilerek kişilerin tüm ihtiyaçlarına cevap verebilecek yaşam alanlarının oluşturulması sürdürülebilirlik açısından sunulabilecek çözümlerden biri olarak görülmektedir. Aksi takdirde projeler ile hedeflenen yaşam alanları terkedilmeye mahrum kalacaktır. Genç nüfusun yoğun olduğu ülkelerde eğitim ve iş nedeniyle pek çok kişi ya arazilerini işleyememekte ya da etkin ve verimli şekilde kullanamamaktadır. Bu amaçla kurulacak bir kurum her açıdan verimliliği arttıracak ve tarımın gelişmesi açısından faydalı olacaktır. Toplulaştırma projelerinin daha hızlı ve sağlıklı bir şekilde yürütülebilmesi için; yatırımların en kısa sürede yapılabileceği köylerin dikkate alınması, yeni parseller oluşturulurken sosyal ve kültürel unsurlar göz önünde bulundurulması, bunun için araştırma enstitüleri ve üniversiteler etkin olarak kullanılması çözüm önerileri arasında yer almaktadır. Çalışan teknik personelin sürekliliği ve güvenilirliği hem kamulaştırma hem kentsel dönüşüm hem de toplulaştırma uygulamalarında çok önemli görülmektedir. Özellikle üniversitelerden destek alınarak ilerlenmesinin güven unsuru açısından oldukça büyük fark yaratacağı düşünülmektedir. Alanda oluşabilecek iki başlılık sorunlarından ötürü kaygı yaşanmaması ve sürecin hızlı bir şeklide yürüyebilmesi için mümkünse bu uygulamaların tek bir kurum tarafından yapılması daha sağlıklı olacaktır.

Türkiye'de halk katılımının sağlanabilmesi amacıyla 2/3 çoğunluk aranması, ilanların 15 gün süre ile askıda kalması, yerel gazetelerde yayınlanması ve uzlaşmaya öncelik verilmesi gibi yöntemler kanunlarla getirilmiştir. Ancak uygulamada halk katılımının birçok nedenden dolayı sağlanamadığı görülmektedir. Arazi edinim uygulamalarında halk katıl1mının sağlanabilmesi ile genel olarak halkın bilgilendirilmesi ifade edilmektedir. Halk katılımının tam anlamıyla sağlanabilmesi yüksek maliyetleri de beraberinde getireceğinden her hak sahibinin ve ilgilinin katılımı ile tüm ilgililerin ortak paydada buluşabilmelerini sağlayabilmek çok kolay olmamaktadır. Halkın bilgilendirilmesi süreçleri de proje süresini uzatmakta olup Türkiye örneğinde mümkün olan en kısa sürede bitirilmek istenen projeler açısından incelendiğinde yetersiz kalmaktadır. Avrupa ülkelerinde bu süreçler oldukça uzun olmakta ve halkın bilgilendirilmesine yeterli süreler ayrılmaktadır. Yetersiz bilginin olduğu projelerde 
güven unsuru azalmakta ve projeler hedeflenen amaçlara ulaşamamaktadır. Bu nedenle düşük maliyetlerle katılımın sağlanabilmesi için farklı yaklaşımlar geliştirilmesi önerilmektedir.

Örnek projelerde görülmektedir ki yasal mevzuat gereği kamu yararı kararı alındıktan ve plan yapıldıktan sonra halk bilgilendirilmekte ancak bilgilendirme zamanı karar verici açısından müdahalenin geç olduğu bir zamana denk gelmektedir. Bu açıdan projenin ilk aşamasından itibaren karşılıklı bilgi alışverişinde bulunulması projelerin çok daha hızlı bir şekilde ilerlemesi ve uzlaşma oranlarının yüksek olması sonucunu ortaya çıkaracaktır. Kamu yararı amacından yola çıkılarak yapılan uygulamalarda bölge halkının ihtiyaçlarına cevap verilebilmesi için o bölgenin hem ekonomik hem de sosyo-kültürel unsurlarına hakim olabilmek önemli bir etkendir. İlgili alanlarda yaşayanların büyük çoğunluğu uygulanan projeler sonucu ne olacağını dahi bilmemektedir. Bu durum ilanların gerçekten amacına hizmet edememekte olduğunu göstermektedir. Gelişmiş ülkelerin çoğunda halk toplantıları düzenlenerek yerel sakinlere projeler ve hedefleri anlatılmakta, onlardan gelecek fikirler doğrultusunda ilerleme kaydedilmektedir.

\section{Arazi Edinim Uygulamalarında Halk Katılımı Açısından Dünya Örneklerinin İncelenmesi}

Her ülke kendi yönetim yapısına uygun kanun ve yönetmelikler çıartarak hem kamunun hem de taşınmaz maliklerinin menfaatlerini koruyacak uygulamalar haline getirmeye çalışmıştır. Farklı uygulamalara rağmen en önemli ilke, kamunun ihtiyacı olan arazi sahiplerinin zarara uğratılmayacak şekilde çözüm üretilmesidir.

İngiltere' de gerçekleştirilecek olan projeler henüz proje aşamasında iken ilgili kurumun sayfasında detaylı şekilde paylaşılmaktadır. Bu sayede ilk aşamada mevcut itirazlar öne sürülerek, ileride doğması muhtemel sorunların önüne geçilebilmektedir. Online şekilde duyuruların yapılması ile daha fazla kişiye ulaşılabilmektedir. İlk duyurudan kısa bir süre sonra yüz yüze toplantılar gerçekleştirilmekte ve paydaşlar ile proje tanitılmaktadır. Bu süreçte projenin yürütülmesine ilişkin ortak bir fikir geliştirilmesi amaçlanmakta ve ileriki aşamalarda da online olarak sürekli bilgilendirmeler yapılmaktadır. Aynı zamanda her süreçte itiraz etme hakları da bulunmaktadır. Özellikle arazi toplulaştırma mevzuatı, arazi sahiplerinin tüm planlama/karar verme sürecine kapsamlı bir şekilde katılımını sağlamaktadır (Demetriou, 2014, s. 26). 
Almanya'da mevcut arazi edinim uygulamalar, 1949 tarihli Kanun'un 14. maddesi ile düzenlenmiş olan Federal Building Act ile yürütülmektedir. Almanya'da plan amaciyla arazilerin elde edilmesinde; kamulaştırma, zorunlu arsa ve arazi düzenlemesi ve sınır düzeltmesi olarak üçlü bir ayrıma gidilmektedir. Kamulaştırma işlemlerinde bedel, yaklaşık 60 yıldır sorumlu bir kurul tarafından tespit edilmektedir. Kamulaştırma sonrasında oluşacak değer artışları kamulaştırma bedeline eklenmediğinden kamulaştırma bedellerinin düşüklüğü ile ilgili şikayetler gelmektedir. Kamulaştırma amacıyla büyük ölçüde kırsal araziye ihtiyaç duyulması halinde özel amaçlı arazi toplulaştırması yapılabilmektedir. Almanya'da yapılan arazi toplulaştırmalarının \% 17'sini kamulaştırma amaçlı arazi toplulaştırmaları teşkil etmektedir (Ayten, 2015, s. 32). Almanya'da Danıştay kamulaştırma karşılığı alınacak bedeli, bir cismin aynadaki görüntüsü ile karşılaştırmakta, böylece alınacak bedelle aynı taşınmaz malın aynı yerde serbest fiyatla satın alınabilmesinin sağlanmasını vurgulamaktadır (Yıldız, 1995). Almanya' da mevcut kamulaştırma amaçlı arazi toplulaştırması çalışmalarında özellikle; eski taşınmazlardaki hakların iyileştirilmesi, bütün taşınmaz sahiplerince değer orantılı karşılanması, taşınmaz mal mülkiyetinin korunması ve maliklerin çıkarının göz önünde tutulmasina dikkat edilmektedir.

Hollanda' da arsa ve arazi edinim işlemleri Kamulaştırma Kanunu (Onteigeningswet) çerçevesinde yürütülmektedir. 1981 yılında çıkartılan bu Kanun'a göre karayolları, demiryolları, altyapı çalışmaları ve kamu binaları için gerekli olan arsa ve araziler elde edilmektedir. Bu Kanun'a göre kamunun ihtiyacı olan araziler için öncelikle kamulaştırma kararı alınmalıdır. Bu karar alındıktan sonra detayları ve gerekçeleri ayrıntılı olarak belirtilen bir rapor yazılmakta, elde edilen bilgiler ve raporlar doğrultusunda kamulaştırma planları yapılmaktadır. Planlar kesinleştikten sonra kamulaştırma kararı Resmi Gazete'de yayınlanmakta ve tamamlanan çalışmalardan sonra arazi satın alma komitesi kurulma, satın alma komitesi, kamulaştırmaya tabi tutulacak arsa ve arazi sahipleriyle ile birlikte değerleme çalışmalarını yapmaktadır. Değerleme çalışmaları günün şartlarına göre ve arazinin gelecekte alacağı değer artışları da göz önünde bulundurularak tamamlanmaktadır. Gelecekteki değer artışı tahmin edilemiyorsa daha sonra uygulamak için bir katsayı belirlenmektedir. Değerleme işlemlerinin objektif olması ve günün rayiç bedellerini yansıttığı için arsa ve arazi sahiplerinin tespit edilen fiyatlara çok itiraz etmedikleri görülmüştür. Arazi sahipleri ile pazarlık yapılabilmekte, pazarlık yapılırken başka 
yerde arazilerle takas teklifinde de bulunabilmekte, anlaşma olması halinde anlaşma belgeleri imzalanmakta ve anlaşılan bedeller üç ay içinde ödenir ayrıca anlaşma olmazsa mahkeme yoluna başvurulabilmektedir.

Hollanda'nın kuzeyinde yer alan Drentsche Aa Bölgesi'nde yapılmış olan bir çalışma örnek teşkil etmesi açısından önemlidir. Hollanda'da büyük ölçekli tarım modernizasyonu ve arazi toplulaştırmasıyla ayakta kalan birkaç alandan biri olan alanda çayırların çoğu, Hollanda Devlet Orman Hizmeti'ne aittir. 1970'lerden 1990'ların başına kadar, Drentsche Aa'nın politikaları, bölgenin benzersiz peyzaj özelliklerini korumaya ve ekonomik kalkınma (çoğunlukla turizm ve tarım) için bir alan sunmaya dayanmaktadır. Ancak, 1993 yılında milli parklar için hazırlık yapan ön hazırlık komisyonunun Drentsche Aa'nın bir milli park olarak tasarlanmasını tavsiye ettiği zaman sorunlarla karşılaşılmıştır. Yerel çiftçiler tarafından bu teklife şiddetle karşı çıkılmıştır. Komite bu durumun milli park oluşturma planlarını tehlikeye attığını fark ederek katılımcı süreçleri başlatmayı önermiştir. Katılımın mevcut itirazları kaldırabileceğine ve milli parka destek sağlayabileceğine inanılmıştır. 1999 yılında hükümet yetkilileri, Drentsche Aa Bölgesi'nin tasarım ve yönetimini müzakere etmek için çok paydaşlı bir platform kurmaya karar vermişlerdir. Ayrıca, çok paydaşlı platformların dışında, bilgilendirme ve tartışma toplantıları şeklinde katılım sağlanmıştır. Bu toplantılar ile platformda yer almayanların söz sahibi olmaları için bir fırsat sunulmuştur. Bazı vatandaşlar tartışma ve bilgilendirme toplantılarına katılmayı istemiş ancak hayal kırıklığına uğramışlardır; çünkü her şeyin çoktan karar verildiği ve hiç kimsenin görüş ve fikirleriyle gerçekten ilgilenmediği izlenimine kapılmışlardır. Sonuç olarak, bu vatandaşlar toplantılara gelmeyi bırakmışlardır. Bir kısmı ise korumanın bu kadar önemli olmadığı kanaatine vararak katılımın tarafı olmamayı seçmişlerdir. Bu çalışma ile, katılımın sadece vatandaşların temsil edildiği tarafsız bir yer değil, farklı vatandaş kategorileri yarattığı savunulmaktadır (Turnhout vd., 2010, s. 11). Çok paydaşlılıktan yola çıkılarak yapılmış olan çalışmada farklı gruplar ve devlet arasında uzlaşma zemini sağlanamamıştır. Halk katılımının sağlanması aşamasının planlar yapıldıktan sonra gerçekleşmesi de halkın görüşlerine gerçek anlamda önem verilmediği kaygısını beraberinde getirmiş ve katılım konusunda isteksizliği arttırmıştır. Halk katılımının sağlanması açısından iyi bir örnek olarak gösterilen Hollanda için bu uygulama başarısızlıkla sonuçlanması yanlış politikaların yerel halk içinde ayrışmalara yol açmasını göstermesi açısından önemli görülmektedir. 
Fransa'da 1935 yılında kamulaştırma kararı devlet tarafından alınırken, bedel tespiti ise yerel halktan oluşan bir jüri ile sağlanmıştır. 1955 yılında arazi fiyatlarındaki artış ve yerel demokrasinin gelişmesi ile birlikte sayıs1 36.000'i bulan yerel idare için daha belirgin standartlar geliştirilmesi amaciyla yeni bir yasal düzenleme getirilmiş ve serbest değerleme komisyonlarının yetkisi kısıtlanmıştır. 1958 yılında bu sistemin yeterince işlemediği ve tıkanıklıklara yol açtığı tespit edilerek, yerel mahkemeler değer tespitleri için görevlendirilmiştir. Bir süre sonra bu uygulamadan da vazgeçilmiştir (Akyol vd., 1992, s. 159).

1990 yılı itibariyle, Japon nüfusunun yaklaşık \% 80'i ve Koreli nüfusun $\% 75$ 'i şehirleşmiştir ve sırasıyla yıllık ortalama $\% 0,7$ ve $\% 3,5$ oranında artmaktadır. Hindistan ve Nepal'de toplam nüfusun \% 27'si ve \% 10'u kentleşmiştir. Parsellere ayrıldıklarında, arazilerin büyüklüğü yavaş yavaş azalmaktadır. Bu süreç, parçalanmış bir arazinin aynı zamanda birkaç parsele daha da bölünmesiyle daha sorunlu hale gelmektedir. Örnek olarak Pakistan'da, 1980 yılında 4,07 milyon olan arazi stoku sayısı 1990'da 5,07 milyona yükselmiştir. Nepaldeki arazilerin yanı sıra parsel sayısı da önemli ölçüde artmış, arazi ve parsel büyüklükleri sırasıyla \% 17 ve \% 8 oranında azalmıştır. 1990'larda ortalama 0,75 hektarlık bir arazi büyüklüğünün dört parsele ayrıldığı Nepal'de, her biri yaklaşık 0,19 hektara düşmüştür. Bu nedenle Güney Asya ülkeleri arazi toplulaştırmasını teşvik etmek için bazı çabalar göstermiştir (Niroula ve Tahapa, 2004, s. 358-359). Örneğin, Hindistan, 1960'lı yılların başlarında bir arazi birleştirme programı uygulamış ve 1970'li yıllarda kooperatif bir çiftçilik yoluyla yapılan gönüllü toplulaştırma Hindistan'da başarısız olmuştur. Biraz ilerleme kaydetmek ve arazi toplulaştırma sürecini hızlandırmak amacıyla 1980 y1lında çıkarılan Arazi Toplulaştırma Kanunu'na dahil edilmiştir. Bu yetki, gerekli hallerde, kamu yararına zorunlu toplulaştırmaya teşvik eder niteliktedir. Punjab'da, ekilen alanın dörtte üçünden daha azına sahip olmayan toprak sahiplerinin üçte ikisinin toplulaştırma talep ettiği köylerde toplulaştırma gerçekleştirilmiştir. Çiftçiler, tahsis edilecek arazinin kalitesi konusunda tam olarak emin olamadıklarından herhangi bir verimli toprak parselini kaybetmek istememişlerdir. Arazi kalitesinde çok fazla değişiklik olmadığı ülkelerde, arazi toplulaştırması uygulamasının başarıyla uygulandığı dikkati çekmektedir (Niroula ve Tahapa, 200, s. 366).

Pakistan Çevre Koruma Yasası'nın (1997) 12 (3) numaralı bölümünde halkın katılımı ve çevresel etki değerlendirmesinde yetkili makamın bu- 
lunması zorunlu kılınmıştır. Ayrıca, Pakistan Çevre Koruma Ajansı Yönetmeliği'nin 10. bölümü, katılımın kamuya açıklanmasının veya halkın davet edilmesinin, İngilizce veya Urduca ulusal bir gazetede yayınlanmasinı ve 30 gün önce proje alanlarında yerel bir gazete tarafindan ilan olunmasını gerektirmektedir. Kamuya bildirimde ayrıca, proje türü, yeri, sahibinin adı ve adresi ve çevresel etki değerlendirme raporunun erişilebileceği yerler hakkında bilgi bulundurulması gerekmektedir. Çevresel Etki Değerlemesi (ÇED) incelemesi kurum içi yetkili makam tarafından yürütülmekte, bağımsız uzmanlar da ara sıra yer almaktadır. Çevre Koruma Ajansları yasal olarak ÇED raporunun sunulmasından sonraki 4 ay içinde bir karar ve çevresel onay vermek için yetkilidir. Federal veya İl Çevre Koruma Ajansları'nun kararları aleyhine, kararın tebliğinden itibaren 30 gün içinde Federal / İl Çevre Mahkemesi'ne itiraz edilebilmektedir. Örnek olarak değerlendirilen karayolu projesi için görüşülen kişilerin çoğu (\% 63'ten fazla), gazete aracılığıyla kamuya açık duyurulardan haberdar olmadığını ileri sürmektedir. Bunun nedenleri, projeden etkilenen alanlarda geniş bir dolaşımın olmadığı gazetelerde ilanların yayınlanması, birçok köy sakininin gazete okumuyor oluşu ve okuyanlar için de dikkat çekici bir unsur içermemesi olarak sayılabilmektedir. Katılım sağlayanlar ise ya Çevre Koruma Ajansı tarafından doğrudan ilgili devlet kurumlarının yetkilileri tarafından davet edilmiş ya da komşular aracılığıyla bu konu hakkında bilgi sahibi olmuşlardır. Her bir olayda görüşülenlerin \% 90'ı dini temsilciler aracılığıyla duyurular yapmanın, yerel ağlarda reklam vermenin ve yerel topluluk temsilcilerini bilgilendirmenin ve özellikle Pencap Bölgesi'ndeki alanlardan paydaşları davet etmenin etkili yöntemler olabileceğini öne sürmüş̧ür. Karayolu sektörü için kamuya duyuru, proje tasarımının tamamlanmasından sonra, ancak arazinin satın alınmasından önce yapılmıştır. Bu nedenle, proje tasarımını ve önerilen rotayı değiştirme olasılıkları olduğu tartışma konusudur. Görüşülen kişilerin \% 90'ı́, sadece ÇED aşamasında değil, ÇED hazırlığı sırasında da paydaşlara danışılması gerektiğini vurgulamıştır. Çok azı (\% 10) böyle bir istişarenin ya ihtiyaç duyulmadığı ya da hiç kullanmadığı görüşündedir. Örnek olayda etkilenen kişilere doğrudan ulaşabilmek hem çok maliyetli hem de oldukça zor olmuştur. Halka duyuru oldukça ulaşılabilir bir konumdaki otelde yapılmış olmasına rağmen katılımcıların birçoğu (\% 74) projenin yakınındaki büyük bir kamu alanında yapılmasının daha iyi olacağını belirtmiştir. Arazi kullanımının mekânsal etkileri ve tarımsal ürünlerde düşüş projenin faydalarına muhtemel olumsuz mekânsal etkilerden daha 
fazla önem verildiğinden göz ardı edilmiştir. Projenin Pencap Hükümeti tarafından finanse edilmesi nedeniyle, bir yeniden yerleşim eylem planının gerekli olmadığg görülmüştür. (Nadeem ve Fischer, 2010, s. 40).

Başka bir örnek proje 380 milyon Euro bedelindeki 400mW Vishnuprayag projesidir. Proje; Dhauliganga Nehri'ne 11,3 km'lik bir tünel boyunca Alaknanda Nehri'nin bir yönünü içermektedir. Projeden üretilen gücün büyük bölümünün bölgeden ihraç edilmesi planlanmaktadır. Vishnuprayag projesinden etkilenen köylerdeki insanlara projeyi ilk kez nasıl duydukları sorulduğu ve hepsi uygulamadan önce resmi kanallardan haberdar olmadıklarını belirtmişlerdir. İnsanlar projeden ya dolaylı olarak konuşmalardan ya da meydana gelen çalışmaları görmeleri sonucunda haberdar olmuşlardır. Ankete katılanlar arasında hüküm süren fikir, hükümetin proje bilgilerine daha fazla erişim sağlamış olması gerektiği yönünde olmuştur. Genel olarak, yerel halk hükümetin çıkarlarını kendilerininkinden daha fazla temsil ediyor olarak görmektedirler. Çok sayıda katılımcı, projenin başlamasından önce, halkın görüşlerinin alınmış olması halinde, onların sorunların gündeme getirebileceklerini ve halk protestolarının önlenebileceğini belirtmişlerdir (Diduck vd., 2012, s. 230). Katılımcıların daha etkin katılımın nasıl sağlanabileceğine dair birçok fikir sunduğu görülmektedir. Hak sahipleri ve kamu kuruluşlarına planlamanın normatif ve stratejik aşamalarına katılma fırsatı verilmesi bu aşamada zorunlu görülmektedir. Bunun sonucu olarak karar verme, sanayinin yönetim salonlarından ve hükümet konferans salonlarından alınarak köy ve kasaba topluluklarına dağıtılmalıdır. Her sektörün kendine özgü güçlü yanlarından yararlanan yaratıcı ortaklıklar, projelerden maksimum verim alınmasının zeminini oluşturmaktadır. Proje aşamasında katılımın sağlanması ileride doğacak sorunların temelde çözüm bulmasına olanak sağlamaktadır.

6,2 milyonluk nüfusuna sahip olan Rio de Janerio'ya olan göç 1980'li yıllarda itibaren artarak devam etmiştir (Xavier, 2003, s. 1). Sonucunda ise Rio de Janerio şehrinde çarpik kentleşme ve gecekondulaşma sorunu ortaya çıkmıştır (Aydın ve Çamur, 2016, s. 62). Örnek olarak incelenen bir diğer projede su ve kanalizasyon sistemlerinin yenilenmesi, sosyal alanların inşası, istihdam olanaklarının yaratılması, halkın yaşam standartlarının yükseltilmesi gibi temel amaçlarla yola çıkılmıştır (Şişman ve Kibaroğlu, 2009, s. 7). Projede özellikle kamu ve yerel halk iş birliği öne çıkmaktadır. Bu amaçla projeye dahil olan yerel halkın bankadan kullandıkları krediler veya kendi paraları ile inşaatı tamamlamaları hedeflenmiştir. 
Programa farklı zamanlarda yerel halk, özel sektörden temsilciler ve yerel örgütler de katılmış ve bu sayede paydaşlar arttırılmıştır. Projenin finansmanı, yerel yönetim ve Inter Amerikan Bankası tarafından gerçekleştirilmiştir (Aydın ve Çamur, 2016, s. 62). Söz konusu projede yerel halkın ihtiyaçları ön planda tutularak hem fiziki hem de sosyal anlamda bir dönüşüm yapılması gerekliliği dikkate alınmıştır. Bu nedenle yerel halkın yaşam standartları yükseltilerek mevcut alışkanlıklarını çok fazla değiştirmeksizin yerinde dönüşüm yapılmıştır.

\section{Halk Katılımı Çerçevesinde İncelenen Örnekler ile Türkiye'de Mevcut Uygulamaların Karşılaştırılması}

Her ülke için proje süreçlerine katılımın sağlanması çok önemli olmakla birlikte özellikle gelişmekte olan ülkelerde sosyal sürdürülebilirliğin sağlanabilmesi için daha da önem arz ettiği söylenebilmektedir (Mahdevinejad ve Amini, 2011, s. 412). Almanya gibi toplulaştırma ve kamulaştırma gibi arazi edinimi konusunda literatürde örnek olarak gösterilen ülkelerde fırsat eşitliğinin sağlanabilmesi ve insan haklarına uygun bir şehircilik anlayışının gerçekleştirilebilmesi için tüm aşamalarda katılımın sağlandığı görülmektedir. Ancak Türkiye'de mevcut düzenlemeler ve uygulamalar incelendiğinde katılım süreçlerinin askı süresinden itibaren başladığı dikkat çekmektedir. Seçilen örneklerin aksine Türkiye'de katılımın sağlanması daha sonraki aşamalarda söz konusu olmaktadır. Benzer şekilde Pakistan'da yapılmış olan çalışma sonucunda da sadece ÇED aşamasında değil, ÇED hazırlı̆̆ı sırasında da paydaşlara danışılması talebinin yüksek oranda oluşu bu görüşü desteklemektedir.

İngiltere'de toplulaştırma projelerinde bilgilendirmenin projenin ilk aşamasından itibaren online olarak paylaşıldığı ve bu şekilde sürecin şeffaf bir şekilde yürütüldüğü görülmektedir. Bu sayede çok daha fazla kişiye ulaşılabilmekte ve yapılan itirazlar neticesinde farklı çözüm önerileri geliştirilebilmektedir. Türkiye'de ilgili kurumların online sayfalarında bilgilendirme ve sürece ilişkin paylaşım yapmaları daha fazla kişiye ulaşılabilmesi için bir çözüm önerisi olarak değerlendirilebilmektedir. Ancak İngiltere ve Türkiye arasındaki eğitim ve internete erişim gibi farklılıkların olması başarı oranında önemli bir etken olarak dikkate alınmalıdır. Her ne kadar örnek ülkelerdeki kadar internet kullanımı gelişmemiş olsa da şeffaflı̆̆ın sağlanabilmesi açısından önemli bir fayda sağlayacağı düşünülmektedir. 
Toplulaştırma uygulamalarında arazi bölünmesinin önüne geçebilmek ana hedeflerden biri olarak kabul edilmektedir. Ancak Avrupa ülke örneklerinde verimin artırılması da diğer bir hedef olarak belirlendiği için toplulaştırma uygulamasında daha fazla başarı elde edildiği görülmektedir. Güney Asya ülkeleri ile Türkiye'nin bu noktada olumsuz şekilde benzerlik gösterdiği tespit edilmiştir. Hindistan örneğinde olduğu gibi verimin düşecek olması Türkiye uygulamalarında da sıklıkla dile getirilen endişeler arasında yer almaktadır. Ancak üretim verimliliği yerine rant beklentisi daha çok tartışılır hale gelmiştir. Oysa tüm dünyada kıtlık kavramı üzerine araştırmalar yapılırken ve verimli tarım arazilerinde kayıplar yaşanırken verimlilik üzerinde daha fazla tartışılması gerektiği düşünülmektedir.

Projenin finansmanı başta olmak üzere farklı aşamalarda yerel halk, özel sektörden temsilciler ve yerel örgütlerin katılımının sağlanmasının, diğer bir ifade ile paydaş çeşitliliğin proje alanında yaşayanlar için güven artırıcı bir özellik olduğu Rio de Janerio örneğinde görülmektedir. Türkiye'de de farklı paydaşların katılımıyla gerçekleştirilen proje sayısı her geçen gün artış göstermektedir. Özellikle üniversitelerin yer aldığı projelerde halk katılımının daha fazla sağlandığı ve uzlaşma oranlarının daha yüksek olduğu görülmektedir.

Arazi edinim yöntemlerinde değerin uluslararası standartlara uygun bir şekilde ve literatürde kabul görmüş bilimsel yöntemler ile belirlenmesi de halkın projeye olan güvenini artıran diğer bir husus olarak öne çıkmaktadır. Fransa örneğinde farklı şekillerde kurullar oluşturulduğu görülmekle birlikte Hollanda ve Almanya gibi bir değerleme ofisi kurulmadığ dikkat çekmektedir. Türkiye'de de zaman içerisinde farklı düzenlemeler yapılmaktadır. Kanunlarda kıymet takdir komisyonları yetkilendirilmiş olsa da değere ilişkin birçok dava açıldığı ve değere itiraz edildiği görülmektedir. Bu alanda eğitim almış kişilerin yetkilendirildiği yeni bir tepe kurumun kurulması ile uzlaşma oranlarında artışlar yaşanacağı ve dava sayısının azalacağı düşünülmektedir. Böylece projeler öngörülen sürelerde tamamlanabilecek ve maliyet artışları önlenebilecektir.

\section{Sonuç}

Mülkiyet hakkına dayanan arazi edinim uygulamaları, dağınık ve küçük halde bulunan arazi parçalarının bir araya getirilerek tarımsal verimliliğin arttırılması, kamu yararı çerçevesinde kamunun ve toplumun ihtiyaçlarının karşılanmasını ifade ederken; hukuki, ekonomik ve sosyal içerikli bir 
süreç olarak işlemektedir. Türkiye'deki arazi yapısının çok parçalı olması nedeniyle tarımsal faaliyetlerin sürdürülmesi zor hale gelmektedir. Aynı şekilde miras hukukundan doğan sistem beraberinde anlaşmazlıkları da getirmektedir. Mevcut arazilerin en etkin şekilde kullanılabilmesi için arazi edinim yöntemlerinin uygulanması kamu yararının bir gereği olarak doğmaktadır. Ancak mülkiyet hakkına müdahale niteliği taşıyan bu yöntemlerde halkın katılımının sağlanması birçok yönden önem arz etmektedir. Ancak arazi edinim yöntemlerinin mülkiyet yapısı ile ilişkisi de oldukça önemli bir etken olarak görülmektedir. Zira İngiltere gibi mülkiyetin büyük kısmının devlete ait olduğu ülkelerde kamulaştırma, kentsel dönüşüm gibi uygulamalar çok daha hızlı ve kolay bir şekilde ilerleyebilmektedir.

Karar vericilerin zaman içerisinde katılım süreçlerini yönlendirme riskleri bulunmakla birlikte sürecin her aşamasında birden çok paydaşın katılımıyla bilgilendirme toplantılarının yapılması ve kişilerin projeye dahil edilmesi mevcut risklerin önlenebilmesi açısından önemli bir adım olarak görülmektedir. Farklı paydaşların proje sürecine dahil edilmesi ile muhtemel yönlendirmelerin önüne geçilerek mevcut risk minimize edilebilecektir.

Yatırım öncesi ve yatırım sırasında belirli periyodlarda hak sahiplerinin proje hakkında bilgilendirilmesi proje başarısı açısından önemli bir husus olarak değerlendirilmektedir. Yapılan çalışma ile dünyadan farklı örnekler seçilerek halka duyurunun yapılış zamanı ve katılımın hangi süreçlerde sağlandığı, paydaşların ve değer tespitinin katılım ve uzlaşma üzerindeki etkisi, verimlilik ve rant beklentisinin farklılaşması gibi farklı bileşenler çerçevesinde Türkiye'deki düzenlemeler ve uygulamalar ile karşılaştırılması amaçlanmaktadır. Bu bileşenler doğrultusunda halk katılımının sağlanması ile proje başarısı arasında bir ilişki olup olmadığı sorgulanmaktadır.

Arazi maliklerine arazilerinin en fazla olduğu bölgede veya en büyük parselin bulunduğu yerin etrafında toplanarak ve yerinden arazi verilmeye çalışılması projeye katılımı ve proje memnuniyetini artıracak hususların başında yer almakla birlikte toplulaştırma süreçlerinde halk katımının başarılı bir şekilde gerçekleştirilebilmesi için izlenmesi ve dikkate edilmesi gereken temel hususlar;

Proje alanında yer alan, farklı merkezi ve yerel kurumlar arasında eşgüdümün sağlanması, 
Projenin gerçekleştirileceği alanda yaşayan kişilerin bir listesinin oluşturulmasi,

Önce arazide yer alan hak sahipleri ile tartışıldıktan sonra karar mekanizmasina sunulmasi,

Toplantılar öncesinde ve proje süresince halkı bilgilendirmek amacıyla broşür dağıtılması, anket ve seminer gibi çalışmaların yapılması,

Yapılacak toplantılarda; halkın, proje hakkında bilgilendirilmesi, görüş, soru ve önerilerinin alınması, toplantılarda görseller kullanılarak projenin zamanlamasının net bir şekilde ortaya konulması ve projenin içeriği üzerinde halkın anlayabileceği bir biçimde bilgilendirme yapılması,

Toplantılara alanı ve yerleşik halkı yakından tanıyan muhtar gibi yerel yetkililerin katılımının sağlanması,

Üniversiteden akademisyenlerin katılması ile projeye olan güvenin ve tarafsızlığa olan inancın artırılması

Anlaşılması güç olan mesleki terimlerin kullanılmasından kaçınılması,

Planlamaya dair parsel maliklerinin itirazlarının incelenerek herkesin ulaşabileceği şekilde ilan edilmesi ve

Tüm sürecin şeffaf bir şekilde paylaşılması ve askı yöntemi dışında web sitesi gibi farklı yerlerde de ilan edilmesi ve her aşamada ilgililer ile bilgi paylaşımı yapılması

şeklinde sıralanabilecektir.

Ancak sayılan temel unsurların uygulamasının ülke örneklerinde farklılıklar olduğu görülmektedir. İngiltere gibi bazı Avrupa ülkelerinde ilgili kurumun ve belediyenin sayfasında tüm bilgi ve veriler halka açık bir şekilde yayınlanmaktadır. Eğitim seviyesinin ve internet kullanım oranlarının yüksek olduğu ülkelerde bu yöntem ile katılımın daha yüksek oranlarda olduğu görülmektedir. Bunun sonucu olarak uzlaşma oranları artmakta ve sonrasında açılan davalar azalmaktadır. Zira bu şekilde çok daha fazla kişiye ulaşılabilmekte ve görüşlerini sunma imkanı verilebilmektedir. Projenin bir parçası olduğuna inanarak görüşlerini paylaşan hak sahipleri proje başarısında önemli aktörler olarak ön plana çıkmaktadır. Ancak bilgilendirmenin eksik olduğu ve katılımın sağlanamadığı ya da yetersiz kaldığı projelerde proje alanının terk edildiği, tarım arazilerinin verimsizleştiği ve uzayan süreçler nedeniyle proje maliyetlerinin arttığı görülmektedir.

Sosyal etki değerlemeleri çalışmalarının ÇED raporları gibi zorunlu hale getirilmesinin çözüm önerisi olarak değerlendirilmesi önemli görülmektedir. Yerel halkın ihtiyaçları, beklentileri ve kaygılarının araştırılarak 
doğabilecek zararların ortaya konulabilmesi ve tazmininin sağlanabilmesi açısından sosyal etki değerlemesinin yapılması da bir diğer önemli husus olarak kabul edilmektedir. Bu şekilde uygulamaya yönelik ön yargılar ve bilgi kirliliği giderilebilecektir. Diğer yandan yüksek oranda katılımın sağlanması ile projeye olan inanç ve bağlılığın artacağı ve bu şekilde kentsel dönüşüm projelerinde dönüşüm alanında gerçekleşen göçlerin önüne geçilebilmesi, toplulaştırma projelerinde arazi veriminin artırılabilmesi gibi amaçlanan hedeflerin gerçekleştirilmesinin daha kolay olacağ düşünülmektedir.

Üniversitelerin sürece dahil edilmesi de tarafsızlı̆̆ın sağlanarak güven unsurunun arttırılabilmesi açısından önemli görülmektedir. Bölge halkının arazi kullanım politikaları ve gelenekleri değerlendirilerek her bölgeye özel uygulamaların yapılmasına öncelik verilmesi gerektiği düşünülmektedir, aksi takdirde istenilen amaca ulaşllamamakta ve hak sahipleri tarafından projeler benimsenmemekte ve sürdürülebilirlik sağlanamamaktadır. Bölge halkının kaygılarını en aza indirgeyecek şekilde bilgilendirme toplantılarının yapılması belki de projenin başarısı için en önemli unsur olarak dikkati çekmektedir. Sonrasında açılacak olan davalar hem süreci uzatmakta hem de çok yüksek tazminatları beraberinde getirmektedir. Avrupa İnsan Hakları Mahkemesi'nde Türkiye'nin taraf olduğu davalar arasında kamulaştırma gibi arazi edinim uygulamaları çok geniş bir yer tutmaktadır. Katılımın sağlanabilmesi bu davaların da zaman içinde azalması sonucunu doğuracaktır. Plan aşamasından başlayarak halkın gerçek anlamıyla bir parçası olduğu uygulamalar çok daha sürdürülebilir olacak ve kamu yararı çerçevesinde etkin ve verimli kullanımı sağlayacaktır. 


\section{Extended Abstract}

\section{Examining Land Acquisition and Public Participation based in Turkey and Other Countries Examples in the World}

\author{
Yeşim Tanrivermiş \\ ORCID: 0000-0002-0859-7150
}

\author{
Esra Keskin \\ ORCID: 0000-0003-2778-9024
}

Rapid urbanization and population growth increase the need for fertile agricultural lands in Turkey and in the world day by day. In particular, rural areas have shrunk as a result of practices such as allotment and sale transactions by the owners, fragmentation as a result of inheritance and expropriation, resulting in a decrease in agricultural activities. One of the structural problems in Turkish agriculture is the small and fragmented enterprises. According to TUIK 2018 data, the average land size in Turkey is 5.16 ha and the number of parcels per enterprise is 5.4. In rural areas, it is mostly unknown who owns the lands, who uses them, which land is cultivated by the real owner, and which land is used by its tenants. Among the reasons for this situation, the regulations on inheritance and especially the regulations in the Law No. 5403 can be counted.

The purpose of land acquisition practices based on the right of ownership is to increase agricultural productivity by bringing together scattered and small pieces of land, to meet the needs of the public and society within the framework of public interest, and especially to make on-site transformation. Consolidation practices in order to combine the shrinking pieces of land take different forms all over the world. However, ensuring public participation is considered as a priority element in terms of successfully ending and managing the process. In the study, it is aimed to compare the current regulations and practices in Turkey within the framework of different components such as the time of public announcement and the processes in which participation is achieved, the impact 
of stakeholders and valuation on participation and reconciliation, differentiation of productivity and rent expectation, by choosing different examples from the world.

In the sample projects selected from Turkey, it is seen that the public is informed after the public interest decision is taken and the plan is made, but the time of informing coincides with a time when the intervention is late for the decision maker. In this respect, mutual exchange of information from the first stage of the project will result in a much faster progress of the projects and higher agreement rates. Since the purpose of public interest is essential, it is an important factor to be able to dominate both the economic and socio-cultural elements of the region in order to respond to the needs of the people of the region. In practice, it is seen that the majority of the people living in the land consolidation areas have no idea about the results of the implemented projects. Trying to give land to the land owners in the region where the lands are the most and from the place is one of the issues that will increase the participation in the project and the project satisfaction. For successful public participation in consolidation processes it is considered necessary to follow some steps such as; ensuring coordination between different central and local institutions in the project area, creating a list of people living in the area where the project will be carried out, presenting them to the decision mechanism after first discussing with the right holders in the land, distributing brochures to inform the public before the meetings and during the project, surveys and seminars carrying out such works, in the meetings to be held; informing the public about the project, taking their opinions, questions and suggestions, revealing the timing of the project clearly by using visuals in the meetings and providing information on the content of the project in a way that the public can understand, ensuring the participation of local authorities that know the area and the residents closely, and academicians from the university, avoiding the use of professional terms that are difficult to understand, and examining the objections of the land owners regarding the planning and announcing them in a way that can be accessed by everyone.

In most developed countries, public meetings are held to explain the projects and goals to local residents, and progress is made in line with ideas from them. Each country has tried to enact laws and regulations that are suitable for its own administrative structure and to make them into practices that will protect the interests of both the public and the land owners. Despite the different applications, the most important principle is to produce solutions so that the land owners will not be harmed. Although it is very important for each country 
to ensure participation in the project processes, it should be emphasized that it is considered even more important to ensure social sustainability, especially in developing countries.

On the other hand, in some European countries such as England, it is seen that the project area is abandoned, agricultural lands become inefficient and project costs increase due to prolonged processes in projects where information is lacking and participation is not provided or insufficient.

Making social impact assessment studies compulsory like EIA reports is considered important as a solution proposal. Researching the needs and expectations of the local people and providing compensation will be possible through social impact assessment. In this way, prejudices and information pollution regarding practice will be eliminated.

The participation of universities in the process is also considered important in terms of increasing the element of trust by ensuring impartiality. The most important factor for the success of the project is the fact that information meetings are held in a way that will minimize the concerns of the people of the region. The lawsuits to be filed both prolong the process and bring very high compensations. Starting from the plan stage, the practices in which the public is a real part will be much more sustainable and will ensure effective and efficient use within the framework of the public interest.

\section{Kaynakça/References}

Aktaş, E., Bilgili, M.E., Akbay, A.Ö. ve Bal, T. (2006). Adana İli Karataş İlçesi Yemişli Köyünde arazi toplulaştırması kararını etkileyen sosyo-ekonomik faktörlerin belirlenmesi. Türkiye VII. Tarım Ekonomisi Kongresi. 18.10.2020 tarihinde https://www.tarekoder.org/2006---antalya---vii--tarim-ekonomisi-kongresi adresinden erişildi.

Akyol, N., Yomralığlu, T. ve Uzun, B. (1992). Türkiye'de ve Gelişmiş Bazı Ülkelerde Kamulaştırma Çalışmaları. Türkiye'de ve Gelişmiş Bazı Ülkelerde Kamulaştırma, İmar Planlarının Uygulanması Semineri, Karadeniz Teknik Üniversitesi, Jeodezi ve Fotogrametri Mühendisliği Bölümü, 157-165.

Arslan, F. ve Değirmenci, H. (2016). Çiftçilerin arazi toplulaştırma projesine bakışı: Kahramanmaraş Türkoğlu İlçesi ve köyleri. Uludağ Üniversitesi Ziraat Fakültesi Dergisi, 30(2), 23-34.

Aydın, A. H. ve Çamur, Ö. (2016). Kentsel dönüşüm uygulamalarında başarılı dünya örnekleri: Danbara, Solidere, Rio De Janeiro. Researchgate, 6(1), 53-68. 
Ayten, T. (2015). Kamulaştırma amaçlı arazi toplulaştırması (Doktora tezi). Selçuk Üniversitesi Fen Bilimleri Enstitüsü, Harita Mühendisliği Anabilim Dalı, Konya. (390319).

Boyraz, Z. ve Üstündağ, Ö. (2008). Kırsal alanlarda arazi toplulaştırma çalışmalarının önemi. e-Journal of New World Sciences Academy, 3(3), 563- 578.

Demetriou, D. (2014). Land consolidation. The development of an integrated planning and decision support system (IPDSS) for land consolidation, 39-66, DOI:10.1007/978-3-319-02347-2_3.

Diduck, A., Sinclair, J., Pratap, D. ve Hostetler, G. (2012). Achieving development: case studies from Chamoli District, Uttarakhand, India. Impact Assessment and Project Appraisal, 25(3), 219-231. https://doi.org/10.3152/146155107X217299.

Ertaş, M. (2011). Kentsel dönüşüm çalışmalarında sosyal boyutun incelenmesi, Ankara ve Londra örnekleri. Selçuk-Teknik Dergisi, 10(1), 1-18.

Kılıç Seyyar, E. (2019). Arazi Toplulaştırma çalışmalarının sosyal ve ekonomik yönden analizi: Kırıkkale İli - Delice İlçesi köy toplulaştırma örneği (Yüksek lisans tezi). Ankara Üniversitesi, Fen Bilimleri Enstitüsü, Gayrimenkul Geliştirme ve Yönetimi Ana Bilim Dalı, Ankara. (558214).

Mahdevinejad, M. ve Amini, M. (2011). Public participation for sustainable urban planning in case of Iran. Procedia Engineering, 21(2011), 405-413.

Nadeem, O. ve Fischer B. T. (2010). An evaluation framework for effective public participation EIA in Pakistan. Environmental Impact A, Review, 31(2011), 36-47.

Niroula S. G. ve Thapa B., G. (2004). Impacts and causes of land fragmentation and lessons learned from land consolidation in South Asia. Land Use Policy, 22(4), 358-372.

Pektaş, K. A. ve Akın, F. (2010). Avrupa Kentsel Şartları perspektifinde bir kentli hakkı olarak katılım hakkı ve Türkiye. Afyon Kocatepe Üniversitesi İktisadi ve İdari Bilimler Fakültesi Dergisi, 12(2), 23-49.

Şağban, M. (2018). Arazi toplulaştırmasının sosyal sonuçları (Yayımlanmamış dönem projesi). Ankara Üniversitesi, Fen Bilimleri Enstitüsü, Gayrimenkul Geliştirme ve Yönetimi Ana Bilim Dalı, Ankara.

Şişman, A. ve Kibaroğlu, D. (2009). Dünyada ve Türkiye'de kentsel dönüşüm uygulamaları. 12. Türkiye Harita Bilimsel ve Teknik Kurultayı. 21.10.2020 tarihinde https://www.hkmo.org.tr/resimler/ekler/0e6be4ce76ccfa7_ek.pdf adresinden erişildi.

Turnhout, E., Van Bommel, S. ve Aarts, N. (2010). How participation creates citizens: participatory governance as performative practice. Ecology and Society, 15(4), 26.

Xavier H. N. (2003). The Case of Rio de Janeiro. Urban Slums Reports: The Case of Rio de Janeiro, Brazil.

Yıldız, N. (1995). Kalkınma planlarında kamulaştırma ve ödentilerinin alternatifleri. Yeniden Yerleşim Planlaması, Uygulaması, İzleme ve Rehabilitasyonu Semineri, Ankara, 40-52. 